\title{
How much sea turtle bycatch is too much? A stationary age distribution model for simulating population abundance and potential biological removal in the Mediterranean
}

\author{
Paolo Casale ${ }^{1,2, *}$, Selina S. Heppell ${ }^{3}$ \\ ${ }^{1}$ Department of Biology and Biotechnologies ‘Charles Darwin,' University of Rome ‘La Sapienza,' Viale dell'Università 32, \\ 00185 Rome, Italy \\ ${ }^{2}$ Centre for Ecology \& Conservation, University of Exeter, Cornwall Campus, Penryn, Cornwall TR10 9FE, UK \\ ${ }^{3}$ Department of Fisheries and Wildlife, Oregon State University, Corvallis, OR 97331, USA
}

\begin{abstract}
Mediterranean populations of loggerhead Caretta caretta and green sea turtles Chelonia mydas are subject to several anthropogenic threats, with documented mortality from incidental capture in fishing gear. However, how such mortalities actually affect the populations is uncertain without an estimate of population size. We derived a theoretical demographic structure for each species in the Mediterranean, assuming a stationary age distribution in a stable population with constant proportions of turtles in each life stage, using distributions of age-specific vital rates. We incorporated uncertainty into the main vital rate parameters to identify a likely order of magnitude of turtle abundance in different life stages. Through this approach, we aim to (1) provide a rough estimate of all population stage classes, particularly the juvenile classes that are most subject to fisheries interactions, (2) provide an estimate of reproductive life span, (3) identify and review the key demographic parameters, and (4) identify the priority gaps in our information in need of further investigation. The range of population abundance estimates from the models constructed with uncertainty $(95 \%$ CI) was $0.81-3.38$ million loggerheads and $0.26-2.21$ million green turtles, Mediterranean-wide. When we calculated the potential biological removal for the segment of the population at risk of fisheries capture, our estimates were comparable to or lower than the estimated bycatch levels in fisheries. Although the model assumes a stable population and provides only a rough estimate of abundance, these results suggest that the current bycatch level should be regarded as unsustainable for Mediterranean turtle populations.
\end{abstract}

KEY WORDS: Loggerhead turtle $\cdot$ Caretta caretta $\cdot$ Green turtle $\cdot$ Chelonia mydas $\cdot$ Demography Incidental capture

\section{INTRODUCTION}

Three sea turtle species occur in the Mediterranean Sea (Casale \& Margaritoulis 2010): the leatherback turtle Dermochelys coriacea, the green turtle Chelonia mydas, and the loggerhead turtle Caretta caretta. A few leatherback turtles enter the Mediterranean from the Atlantic but do not breed in the basin (Casale et al. 2003), while the other 2 species

\footnotetext{
*Corresponding author: paolo.casale1@gmail.com
}

have Mediterranean populations recognized as regional management units (Wallace et al. 2011).

The loggerhead turtle is the most abundant sea turtle species in the Mediterranean, and reproduces mainly in Greece, Turkey, Cyprus, and Libya (Casale \& Margaritoulis 2010). Loggerhead turtles frequent the entire marine area of the Mediterranean, with high occurrence reported in the oceanic zones of the westernmost part of the basin (from the Alboran Sea

() The authors 2016. Open Access under Creative Commons by Attribution Licence. Use, distribution and reproduction are unrestricted. Authors and original publication must be credited. 
to the Balearic Islands), the Strait of Sicily, and the Ionian Sea. The foraging areas of the western basin are frequented by loggerheads of both the Mediterranean and the Atlantic populations from the Americas (Carreras et al. 2011). Loggerheads are also found in high abundance in the neritic zones of the northern Adriatic, off Tunisia, Libya, Egypt, and the southeast coast of Turkey (Casale \& Margaritoulis 2010). Green turtles primarily frequent shallow neritic areas in the easternmost part of the basin and reproduce on nesting beaches in Turkey, Cyprus, and Syria (Casale \& Margaritoulis 2010).

In the Mediterranean, these 2 sea turtle species are subject to several anthropogenic threats, including degradation of coastal habitats, incidental catch in fishing gear, collision with boats, and intentional killing, mainly for food (Tomás et al. 2008, Casale \& Margaritoulis 2010, Casale et al. 2010, Casale 2011). These anthropogenic impacts appear to increase overall mortality (loggerheads: Casale et al. 2007, 2010, 2015) and as a whole represent a high level of threat for both species (Wallace et al. 2011). Nevertheless, nest counts at monitored nesting beaches do not show a clear trend for the Mediterranean as a whole, with individual nesting beaches showing increases, decreases, or no trend (Ilgaz et al. 2007, Türkozan \& Yilmaz 2008, Casale \& Margaritoulis 2010, Margaritoulis et al. 2011). For instance, no significant trend was observed at the single most important loggerhead nesting site over a 26 yr period from 1984 to 2009 (Zakynthos, Greece; Margaritoulis et al. 2011). However, because sea turtles are long-lived and take many years, even decades, to reach maturity, the population is primarily composed of juveniles, and nest counts are often poor indicators of population status because they are indicators of adults only (Heppell et al. 2002, National Research Council 2010). Likewise, trends based on nest counts can be affected by environmental factors that influence the frequency of reproduction (Hays 2000, Solow et al. 2002, Mazaris et al. 2004).

The main threat for sea turtles at the regional level is probably the mortality induced by incidental capture in fishing gear (Casale 2011). Fisheries bycatch studies usually estimate the number of catches that are then converted to number of deaths if immediate and delayed mortality rates are known. However, these extrapolations do not estimate the decrease in overall survival probability at the population level because the total number of turtles is unknown. For the Mediterranean, Casale (2011) estimated over 132000 turtle captures $\mathrm{yr}^{-1}$ and an associated annual mortality of over 44000 deaths, but how such a loss actually affects local populations is uncertain without an estimate of population size. Only the number of adult females nesting annually in the Mediterranean has been estimated to date (loggerheads: 2280-2787; green turtles: 339-360 (Broderick et al. 2002). However, this represents only a subset of all adult females and a very small part of the total population (Heppell et al. 2002). Therefore, estimating the abundance of the population as a whole would represent a valuable contribution to sea turtle management that could better contextualize the magnitude and potential impacts of bycatch.

Estimates of population abundance will allow application of the potential biological removal (PBR) approach, developed for marine mammals (Wade 1998). This approach is based on the concept that the anthropogenic mortality of a population should not exceed $50 \%$ of the potential maximum productivity rate of the population, adjusted by a recovery factor which can vary from 0.1 to 1 according to the conservation status of the population. If the anthropogenic mortalities are less than the PBR, then a depleted population should recover. PBR is a very simple approach with some basic assumptions, including a logistic population growth curve (in which the maximum net productivity level corresponds to $50 \%$ of the maximum population growth rate). However, differently from marine mammals, the size and demographic structure of sea turtle populations are commonly unknown, and the numbers of nests or adult females are used as abundance indices. In order to overcome this problem and apply PBR to sea turtle populations where only the number of adult females is known, Curtis \& Moore (2013) recently developed a maximum bycatch estimation approach which uses reproductive value equivalents in place of the number of individuals, an approach that includes additional uncertainty represented by the reproductive value equivalents. In this study, we addressed the demographic problem in a different way, by estimating potential distributions of the number of individuals in the age classes subjected to anthropogenic mortality and applying the original and simpler PBR approach. As a first attempt to compare anthropogenic mortalities with population size in the Mediterranean, with the associated uncertainties, scenarios considered as unsustainable were minimized by considering maximum PBR levels derived from total instead of minimum population size.

Simple deterministic age-structured models can be used to estimate population size under the assumption of stable age distribution and constant recruitment when combined with an estimate of adult pop- 
ulation size (Caswell et al. 1998, Heppell et al. 2005). One problem with this method is a lack of adequate information on the juvenile stages, in terms of fundamental parameters such as age at maturity, number of stages (and their duration), and stage-specific survival probability. In previous studies of life-history sensitivity, the number of stages was based on habitat or body size, while the survival probabilities were assumed to be constant within a stage, derived from mark-recapture field studies or size-based catch curve analyses (e.g. Frazer 1983, Crouse et al. 1987, Heppell et al. 2005). In early models, the survival rates for unobservable stages, such as the hatchling and pelagic juvenile stages, were set to achieve an asymptotic population growth rate $(\lambda)$ that matched observed trends on nesting beaches (Frazer 1983, Crowder et al. 1994). Some vital rates have been measured for Mediterranean loggerheads, but considerable uncertainty remains in the estimates for

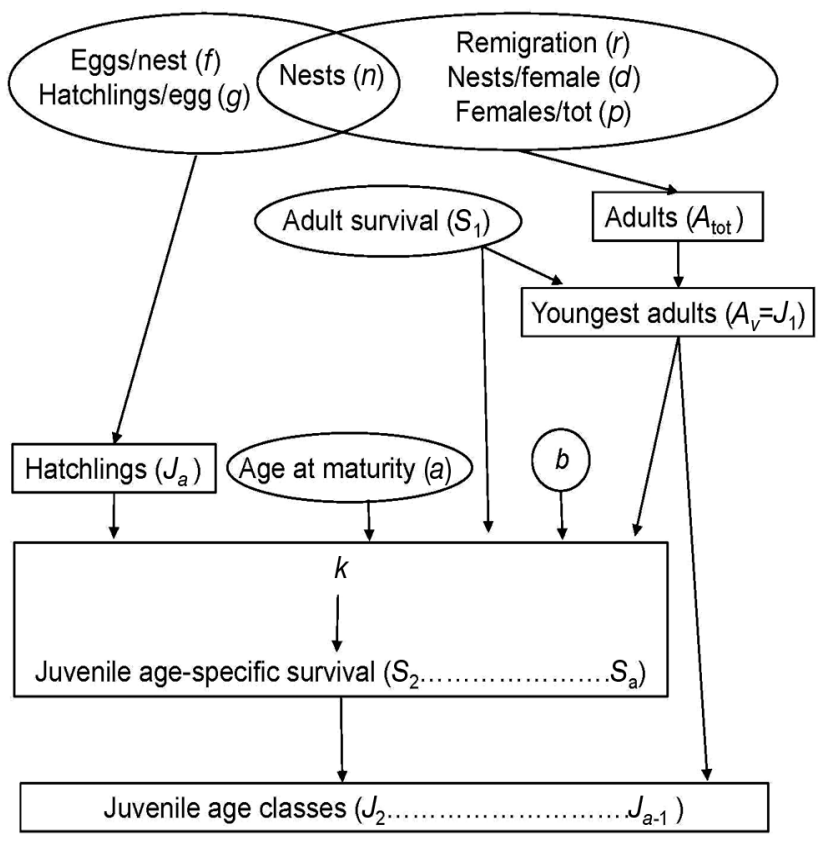

Fig. 1. Main steps of the model to estimate abundance of Mediterranean sea turtle populations. The 9 fundamental (independent) parameters are shown in ellipses/circles (see Table 1), and the derived parameters and variables are shown in boxes. Step 1: random values of the 9 fundamental parameters are generated from given value ranges and distributions (Table 1). Step 2: the number of adults $\left(A_{\text {tot }}\right)$ and hatchlings $\left(J_{a}\right)$ are derived (Eqs. $\left.1 \& 18\right)$. Step 3: the number of adults in the youngest age class $\left(A_{V}=J_{1}\right)$ is derived (Eq. 7). Step 4: the parameter $k$ is derived as a value that determines age-dependent $S$ values which make $J_{0}$ and $J_{1}$ coherent in a stable population (Eq. 17). Step 5: the abundance of each juvenile age class is calculated (Eq. 16). All steps are repeated 10000 times to obtain $95 \%$ CI. $b$ : parameter for nonlinearity of $S$-age relation loggerheads, and demographic data for green turtles are lacking. Nevertheless, an order-of-magnitude estimate of population size for life stages affected by fisheries interactions is possible with some assumptions about population structure and the relationship between body size and annual survival probabilities (Caswell et al. 1998).

To contribute to our understanding of the demography and population size of Mediterranean loggerhead and green turtles, we derived a theoretical demographic structure assuming a stationary age distribution, i.e. stable population and constant proportions of turtles in each life stage, to roughly determine population size. This approach estimates the structure of the juvenile life stage in a way that balances the hatchlings produced by observed clutches and the adults laying those clutches by estimating stationary annual survival rates for each juvenile age class (1 yr class). We incorporated uncertainty into the main parameters to define a range of the order of magnitude of the abundance at different stages. Through this approach, we aimed to (1) provide an estimate of abundance of all population stages, with particular regard to the juvenile class and the part of the population at risk of capture by fishing gear, (2) provide PBR levels and compare them to the known bycatch levels, (3) provide an estimate of reproductive life span, (4) identify and review the key demographic parameters, (5) identify the priority demographic gaps in need of further investigation.

\section{MATERIALS AND METHODS}

Our model aimed to simulate the demographic structure of theoretical sea turtle populations that are as similar as possible to the actual Mediterranean loggerhead and green turtle populations, but ideally under natural conditions, i.e. not considering anthropogenic mortality. However, it cannot be excluded that the given values of some independent variables (e.g. natality) incorporate current anthropogenic effects. The resulting abundance simulations were then compared to known levels of anthropogenic mortality.

\section{Population demographic structure and abundance}

The general approach of our model can be summarized as follows (Fig. 1). From annual nest counts, we derived the annual number of hatchlings (first age class) and the total number of adults. From the latter 
and adult survival, the demographic structure of the adult stage was derived to determine the abundance of the youngest adult age, from which all younger juvenile age classes were derived, working backwards to the first age class (hatchlings). Finally, the model forced this number of hatchlings derived by age class simulation to match the number of hatchlings determined by nest count, under the assumption of a stationary age distribution (constant annual survival rates by life stage and constant recruitment of new hatchlings each year). The resulting agespecific annual survival probabilities were then used to reconstruct the abundance of the juvenile age classes.

For convenience, we modeled the adult and juvenile stage classes separately, defining them on the basis of age at sexual maturity $\left(a_{i}\right.$ also commonly known as ASM) and annual survival probability $(S)$. We defined the adult class as those turtles equal to or older than ASM, and having a constant annual survival probability $\left(S_{1}\right.$, see below). Therefore, this definition is independent from the actual breeding activity that occurred during a given year or age, which is defined by the remigration interval $(r$, see 'Adults' below). The juvenile class included turtles younger than a (ASM) and with a variable annual survival probability depending on age $\left(S_{t}\right.$, see 'Juveniles' below).

\section{Adults}

The first step to estimate population size was to estimate the total number of adults $A_{\text {tot }}$ as:

$$
A_{\text {tot }}=\frac{n r}{p d}
$$

where $n$ is the number of nests $\mathrm{yr}^{-1}, r$ is the remigration interval (years between nesting years, or 1/proportion of adult females nesting in a particular year), $d$ is the number of nests female ${ }^{-1}$ season $^{-1}$, and $p$ is the proportion of adults that are females. This assumes that reproduction parameters and sex ratio are constant for all adult age classes (see 'Model parameters' below).

We then estimated the number of adults in the youngest adult age class. Although this can be estimated from the proportion of adults that are 'neophytes,' or turtles breeding for the first time, we preferred to generate a distribution of the number of adult turtles in all adult age classes for 2 reasons. First, the proportion of neophytes is not well known in the Mediterranean, and this parameter is likely to vary from one nesting site to another, together with the abundance trend. Second, with our approach, we could also estimate the reproductive life span. We assumed a constant annual survival probability and stationary adult age classes. A constant survival probability for each adult age class is plausible because, unlike juveniles, sea turtle adults show reduced or even negligible somatic growth (Carr \& Goodman 1970, Limpus \& Chaloupka 1997, Broderick et al. 2003, Casale et al. 2009b, 2011a). Therefore, if size affects survival, it is unlikely to vary much among adult age classes. Also, adults keep the same lifestyle and frequent the same habitats. Constant adult survival is also supported by some empirical data (e.g. Frazer 1983), and has been commonly applied in sea turtle modeling studies (e.g. Chaloupka \& Limpus 2005, Heppell et al. 2005, Mazaris \& Matsinos 2006, Dethmers \& Baxter 2011, Lamont et al. 2014) With a known total adult abundance and a constant annual survival probability, the number of age classes and their abundances can be easily derived. In this model, the abundance of each adult age class was calculated from the next older age class $\left(A_{t-1}\right)$, where $t$ denotes a specific age class (in adults this ranges from 1 to $v$ ); therefore, from the oldest to the youngest age classes:

$$
A_{t}=\frac{1}{S_{1}} A_{t-1}=\frac{A_{1}}{S_{1}{ }^{t-1}}
$$

where $S_{1}$ is the adult survival probability, and $A_{1}$ is the oldest class which, for convenience, may include more than 1 age class. The sum of all adult age classes equals the total number of adults $\left(A_{\text {tot }}\right)$. If we set $v$ as the number of adult classes (i.e. the number of annual age classes $+A_{1}$ ), then

$$
A_{\text {tot }}=A_{1} \sum_{m=1}^{v} \frac{1}{S_{1}{ }^{m-1}}=A_{1} \frac{1-\left(1 / S_{1}\right)^{v}}{1-\left(1 / S_{1}\right)}
$$

from which $v$ can be derived:

$$
v=\frac{1}{\ln S_{1}} \ln \frac{S_{1} A_{1}}{S_{1} A_{1}+A_{\text {tot }}\left(1-S_{1}\right)}
$$

For convenience, we defined the number of adult annual age classes $(v-1)$ as the number of age classes that include $99.9 \%$ of adults, with the oldest adult class $\left(A_{1}\right)$ including all of the remaining oldest age classes (comprising $0.1 \%$ of adults). In other words, only 1 in 1000 adult turtles would survive until $A_{1}$, and therefore $v-1$ can be regarded as the maximum reproductive life span (e.g. Frazer 1983). Therefore, $A_{1}$ is set as:

$$
A_{1}=A_{\text {tot }} 10^{-3}
$$


From Eqs. (4) \& (5), v can be calculated as:

$$
v=\frac{1}{\ln S_{1}} \ln \frac{S_{1}}{S_{1}+\left(1-S_{1}\right) 10^{3}}
$$

Note that this relation is now independent from $A_{\text {tot, }}$ i.e. the number of adult age classes $V$ can be derived by $S_{1}$ only. The abundance of the youngest adult age class $\left(A_{V}\right)$ was derived from Eqs. (2) \& (5), with $v$ obtained from Eq. (6):

$$
A_{V}=\frac{A_{1}}{S_{1}{ }^{v-1}}=\frac{A_{\mathrm{tot}} 10^{-3}}{S_{1}{ }^{v-1}}
$$

It should be noted that this first adult age class is not equivalent to first-time breeders (neophytes), except in cases when turtles breed every year $(r=1)$. If $r>1$, then only $1 / \mathrm{r}$ of the adults (in any age class) would breed in a given year. The non-breeding fraction of an adult age class will be subject to annual mortality and will then enter the next age class and again have a probability $1 / r$ of breeding, and so on. Therefore, the proportion (c) of female neophytes observed on a nesting beach in a given year is:

$$
c=U_{\mathrm{tot}} \frac{r}{A_{\mathrm{tot}} p}
$$

where $U_{\text {tot }}$ is the sum of the female neophytes of different age classes $\left(U_{m}\right)$ :

$$
\begin{aligned}
U_{\text {tot }} & =\sum_{m=1}^{\mathrm{V}} U_{m}=\sum_{m=1}^{\mathrm{V}} \frac{A_{V} p}{r}\left(\frac{r-1}{r} S_{1}\right)^{m-1} \\
& =\frac{A_{V} p}{r} \sum_{m=1}^{V}\left(\frac{r-1}{r} S_{1}\right)^{m-1} \\
& =\frac{A_{V} p}{r} \times \frac{1-\left(\frac{r-1}{r} S_{1}\right)^{V}}{1-\left(\frac{r-1}{r} S_{1}\right)}
\end{aligned}
$$

Then, combining Eqs. (8) \& (9):

$$
C=\frac{A_{V}}{A_{\mathrm{tot}}} \times \frac{1-\left(\frac{r-1}{r} S_{1}\right)^{V}}{1-\left(\frac{r-1}{r} S_{1}\right)}
$$

Note that if turtles breed every year $(r=1)$, then the proportion of first breeders (neophytes) is equivalent to the proportion of adults in the youngest adult age class $\left(A_{V}\right)$.

In order to describe the age distribution of adults, we calculated the number of age classes that include the youngest $25,50,75$, and $95 \%$ of the adult population $\left(V_{z}\right)$ as follows:

$$
V_{z}=V-V_{1-z}
$$

with

$$
\begin{aligned}
V_{1-z} & =\frac{1}{\ln S_{1}} \ln \frac{S_{1} A_{1}}{S_{1} A_{1}+A_{\text {tot }}(1-z)\left(1-S_{1}\right)} \\
& =\frac{1}{\ln S_{1}} \ln \frac{S_{1}}{S_{1}+\left(1-S_{1}\right)(1-z) 10^{3}}
\end{aligned}
$$

where $v_{z-1}$ is the number of age classes that include the remaining oldest part of the adult population, derived from Eqs. (4) \& (5), with $z$ assuming the value of $0.25,0.50,0.75$, or 0.95 , respectively. Furthermore, the average reproductive life span (ARL) of the adult population was calculated as the sum of the individual reproductive ages divided by the number of adults:

$$
\mathrm{ARL}=\frac{\sum_{t=1}^{V} A_{V} S_{1}{ }^{t-1} \times t}{\sum_{t=1}^{V} A_{V} S_{1}{ }^{t-1}}=\frac{\sum_{t=1}^{V} S_{1}{ }^{t-1} \times t}{\sum_{t=1}^{V} S_{1}{ }^{t-1}}
$$

where $A_{V}$ is the youngest adult age class which, however, disappears in the final step of the formula and is not needed for calculating ARL. Because $v$ is calculated from $S_{1}$ only (Eq. 6), $S_{1}$ is the only parameter needed to calculate ARL.

\section{Juveniles}

The largest fraction of a sea turtle population consists of juveniles, due to high fecundity and the large number of age classes from hatchling to adult. The primary aim of our calculations was to estimate the abundance of juveniles in each annual age class, which we could then sum to obtain the total juvenile population size estimate and the segment of the population at risk of capture by fisheries. Two parameters primarily affect the estimation of juvenile abundance: ASM (a), which determines the duration of the juvenile stage and the number of juvenile age classes, and the annual survival probability $(S)$ of turtles within this stage. Previous models considered $S$ as constant for the entire juvenile class (e.g. Frazer 1986) or for each of a few juvenile stages that included several age classes, with annual survival rates for each stage based on size and derived from field estimates (Heppell et al. 2002). We considered $S$ as a variable dependent on age and hence on size, because annual growth of juveniles is significant (for Mediterranean loggerheads: Casale et al. 2009a,b, 2011a,b, Piovano et al. 2011), and it is reasonable that body size may affect survival through several factors 
such as defense from predators, feeding capability, thermoregulation, etc. We considered $S$ to be a positive function of age and avoided any arbitrary division of the juvenile class into stages (e.g. oceanic and neritic) because such stages are not supported for loggerheads in the Mediterranean context (Casale et al. 2008). Moreover, we allowed $S$ to vary non-linearly with age, because faster change of $S$ is more likely at young ages than at older ages, when turtles are growing more slowly.

The model made the following assumptions: (1) the duration of the juvenile stage (hatchling to adult) is the same for all turtles (i.e. all turtles enter the adult stage at the same age, $a_{i}(2)$ survival probability increases with age, therefore $S$ of a given juvenile age class is higher than that of the previous younger age class; $(2)$ the population is stable and has a stable demographic structure; and (4) all age classes have the same sex ratio.

The abundance of each juvenile age class $J$ was calculated from the next older age class, from the oldest to the youngest:

$$
J_{t}=\frac{1}{S_{t}} J_{t-1}
$$

where $S_{t}$ is the survival probability of the juvenile age class $t$, with $t$ increasing with decreasing age, from 1 to $a$ (number of age classes $=$ ASM). The initial age class $\left(J_{1}\right)$ to calculate all juvenile age classes from $J_{2}$ onward, is actually the youngest adult age class $\left(A_{V}\right.$, Eq. 7) here named $J_{1}$ for convenience (and included in the adult count only, not juvenile), and $J_{a}$ is the youngest juvenile age class (first year of life, i.e. hatchlings). The model considers $S$ as age class-specific, increasing with age, and allows non-linear change of $S$ :

$$
\begin{aligned}
S_{t} & =S_{t-1} \frac{k-1}{k}(a-t+1)^{b} \\
& =S_{1}\left(\frac{k-1}{k}\right)^{t-1}\left[\frac{(a-1) !}{(a-t) !}\right]^{b}
\end{aligned}
$$

where $S_{1}$ is the survival probability of adults, $k$ is a parameter which determines the general slope of the relationship between $S$ and age, and $b$ is the parameter which determines the degree of non-linearity of this relationship. The parameter $b$ was allowed to vary within a range of values between 0 and a maximum value arbitrarily set for each of the models with different a (ASMs, see below) as the maximum value below which $S$ increases with age, ranging from $b=0.01$ for $a=34$ to $b=0.06$ for $a=21$ for loggerhead turtles and from $b=0.001$ for $a=50$ to $b=0.12$ for $a=18$ for green turtles.
From Eqs. (14) \& (15):

$$
J_{t}=\frac{J_{1} \prod_{u=1}^{t}(a-u) !^{b}}{S_{1}{ }^{t-1}\left(\frac{k-1}{k}\right)^{\frac{t^{2}-t}{2}}(a-1) !^{b t}}
$$

from which it is possible to obtain the value that $k$ should have in a stable population, by setting $t=a_{\text {, }}$ with the first age class as $J_{1}\left(=A_{V}\right.$ youngest adult age class) and the last age class as $J_{a}$ (hatchlings, age class 1):

$$
k=\frac{1}{1-\sqrt[\frac{a^{2}-a}{2}]{\frac{J_{1} \prod_{u=1}^{a}(a-u) !^{b}}{J_{a} S_{1}^{a-1}(a-1) !^{b a}}}}
$$

where $J_{a}$ is calculated as:

$$
J_{a}=n f g
$$

where $n$ is the number of nests $\mathrm{yr}^{-1}, f$ is the number of eggs nest ${ }^{-1}$, and $g$ is the number of hatchlings per egg which reach the sea. This 'backward' numeration allowed us to easily vary the total number of juvenile age classes, based on different values of a (ASM).

To estimate distributions of population size with uncertainty, we randomly drew values from predetermined parameter distributions (10 000 replicates) based on previously published estimates or best guess values (Table 1). Monte Carlo simulations were run with the PopTools add-in for Microsoft Excel (www. poptools.org). Separate simulations were run for different a (ASM) values.

\section{Model parameters}

The estimation model is based on 8 fundamental (independent) biological parameters which describe a population $\left(a, n, r, d, p, f, g, S_{1}\right)$ plus the parameter $b$, which controls the degree of non-linear relation between $S$ and age (see Table 1 for values and sources of these 9 parameters). However, 2 of these parameters are particularly important for the model and are described below in detail.

\section{Number of nests per year}

The average number of loggerhead turtle nests $\mathrm{yr}^{-1}, n$, in the Mediterranean based on data available from monitored beaches is about 7250 (Casale \& Margaritoulis 2010). However, this figure represents 
Table 1. Parameters, values, and distributions for a stationary age model of the Mediterranean (Med) loggerhead and green turtle populations. A triangular distribution was adopted if a likely value could be identified; otherwise a uniform distribution within the range was adopted to account for maximum uncertainty. Positive or negative relationships of the individual parameters with the resulting estimate of population abundance are indicated with + and -, respectively. Sources: 1: Broderick et al. (2003), Ilgaz et al. (2007), Hays et al. (2010); 2: Broderick et al. (2003); 3: Rees \& Margaritoulis (2004), Casale et al. (2005, 2006, 2014), Zbinden et al. (2007), Rees et al. (2013), Godley et al. (2001); 4: Broderick et al. (2003), Margaritoulis et al. (2003), Türkozan et al. (2003), Margaritoulis (2005), Özdemir et al. (2008), Türkozan \& Yilmaz (2008); 5: Türkozan et al. (2003), Türkozan \& Yilmaz (2008), Margaritoulis (2005); 6: Heppell et al. (1996, 2002), Monk et al. (2011); 7: Stokes et al. (2014); 8: arbitrary wide range, in order to include high uncertainty, and considering results by Kaska et al. (1998) and Casale et al. (2000); 9: Türkozan et al. (2011); 10: Heppell et al. (2002), Campbell \& Lagueux (2005). Sources given as 'see text' refer to 'Materials and methods: Model parameters'

\begin{tabular}{|c|c|c|c|c|c|c|c|}
\hline Parameters & $\begin{array}{l}\text { Single or } \\
\text { likely } \\
\text { value }\end{array}$ & Min & Max & Distribution & Source & Area & $\begin{array}{c}\text { Effect } \\
\text { on pop. } \\
\text { estimate }\end{array}$ \\
\hline \multicolumn{8}{|l|}{ Loggerhead turtles } \\
\hline Age at sexual maturity (ASM) (a) & $21-34$ & & & & See text & Med & + \\
\hline Nests per year $(n)$ & 8300 & 7250 & 8800 & Triangular & See text & Med & + \\
\hline $\begin{array}{l}\text { Female remigration interval } \\
\text { (years/breeding) }(r)\end{array}$ & 2.3 & 2 & 3.35 & Triangular & 1 & Med & + \\
\hline Nests per female per breeding season $(d)$ & 1.9 & 1 & 5 & Triangular & 2 & Med & - \\
\hline Sex ratio (proportion female) $(p)$ & & 0.40 & 0.75 & Uniform & 3 & Med & - \\
\hline Eggs per nest $(f)$ & & 73 & 116 & Uniform & 4 & Med & + \\
\hline Hatchlings to sea per egg $(g)$ & & 0.583 & 0.666 & Uniform & 5 & Med & + \\
\hline Adult survival $\left(S_{1}\right)$ & & 0.85 & 0.91 & Uniform & 6 & World & - \\
\hline $\begin{array}{l}\text { Parameter for non-linearity of } \\
S \text {-age relation }(b)\end{array}$ & & 0 & $0.01-0.06$ & Uniform & $\begin{array}{l}\text { Arbitrary, } \\
\text { see text }\end{array}$ & & - \\
\hline \multicolumn{8}{|l|}{ Green turtles } \\
\hline $\operatorname{ASM}(a)$ & $18-50$ & & & & See text & Med & + \\
\hline Nests per year $(n)$ & & 1600 & 1840 & Uniform & See text & Med & + \\
\hline $\begin{array}{l}\text { Female remigration interval } \\
\text { (years/breeding) }(r)\end{array}$ & 3 & 3 & 4 & Triangular & 7 & Med & + \\
\hline Nests per female per breeding season $(d)$ & 3 & 1 & 4 & Triangular & 7 & Med & - \\
\hline Sex ratio (proportion female) $(p)$ & & 0.50 & 0.9 & Uniform & 8 & Med & - \\
\hline Eggs per nest $(f)$ & & 103 & 119 & Uniform & 9 & Med & + \\
\hline Hatchlings to sea per egg $(g)$ & & 0.58 & 0.85 & Uniform & 9 & Med & + \\
\hline Adult survival $\left(S_{1}\right)$ & & 0.82 & 0.95 & Uniform & 10 & World & - \\
\hline Parameter for non-linearity of $S(b)$ & & 0 & $0.001-0.12$ & Uniform & $\begin{array}{l}\text { Arbitrary, } \\
\text { see text }\end{array}$ & & - \\
\hline
\end{tabular}

an underestimate, for 2 reasons. First, many nests are scattered along minor or unknown nesting beaches along the Mediterranean coasts; in Greece, these nests are estimated to comprise about $15 \%$ of the monitored ones (Margaritoulis et al. 2003). Second, about $66 \%$ of sandy beaches in Libya (total $1089 \mathrm{~km}$ ) have never been surveyed (Hamza 2010) and might support high nesting levels. We therefore considered 7250 as the minimum, $8300(7250+15 \%)$ as the most likely figure, and 8800 (including 500 hypothetical additional nests from Libya) as the maximum number of nests $\mathrm{yr}^{-1}$ (Table 1).

Based on data available from monitored beaches, the average number of green turtle nests $\mathrm{yr}^{-1}$ in the Mediterranean is about 1600 (Casale \& Margaritoulis 2010). Because additional unmonitored nesting activ- ity probably occurs, we considered 1600 as the minimum number and $1840(1600+15 \%)$ as the maximum number of nests $\mathrm{yr}^{-1}$ (Table 1).

\section{Number of juvenile age classes}

Age at maturity (a) was calculated from the mean values of 8 age-at-length relationships obtained in the Mediterranean through capture-mark-recapture, length-frequency, and skeletochronology (Casale et al. 2009b, 2011a,b, Piovano et al. 2011), The size at maturity of loggerhead turtles in the Mediterranean was assumed to be the average size of nesting females, because female loggerhead turtles begin breeding at a size slightly smaller than the average 
size of all nesting females (Limpus 1990). The mean size (weighted for rookery size in terms of number of nests) of loggerheads nesting in the Mediterranean is ca. $80 \mathrm{~cm}$ curved carapace length (CCL) (see Table S1 in the Supplement, available at www. int-res.com/articles/suppl/n029p239_supp.pdf), and males appear to reach maturity at a similar size (Casale et al. 2005, 2014). The mean age at $80 \mathrm{~cm}$ CCL determined from the 8 growth curves resulted in an average $a$ of $25 \mathrm{yr}$ (range: $21-34 \mathrm{yr}$ ). To consider the uncertainty of these estimations and to provide indications of the effects of $a$ on the model, 14 models were built with a ranging from 21 to 34 yr.

Because no growth curve is available for Mediterranean green turtles, we adopted the highest uncertainty possible for a (ASM) of this species, represented by the range of ASMs estimated for other green turtle populations around the world, viz. 18 to 50 yr (Avens \& Snover 2013). A total of 17 models were built with a (ASM) ranging from 18 to $50 \mathrm{yr}$ (1 model for every $2 \mathrm{yr}$ of possible ASM).

\section{General sensitivity analysis}

The relative importance of each parameter on the population abundance estimate was assessed by comparing results from simulations for the set values of 1 parameter at a time either (1) increased or decreased by $20 \%$ for parameters with positive or negative relationships with population abundance, respectively, or (2) fixed at the minimum and maximum values considered for the model (see Table 1).

\section{Bycatch and PBR}

Segment of the population at risk of capture

Available bycatch data indicate that only turtles $>20 \mathrm{~cm}$ CCL are generally captured (Casale 2011) and were therefore considered to be at risk of capture in our model; this approximately corresponds to turtles older than 2 yr from hatching (Casale et al. 2009a, Goshe et al. 2010). However, this is a minimum size threshold, and such small turtles are not commonly caught (Casale 2011); therefore, we considered turtles $>40 \mathrm{~cm} \mathrm{CCL}$ to be at higher risk of capture. For Mediterranean loggerheads, this size range corresponds to turtles older than $7 \mathrm{yr}$ from hatching (Casale et al. 2009b, 2011a,b, Piovano et al. 2011). The lack of growth data for Mediterranean green turtles makes an estimate of age at that size highly uncertain for this species, so the higher risk category was not considered for green turtles.

PBR

The PBR approach for protected species was developed for marine mammals (Wade 1998) and is based on the concept that the anthropogenic mortality of a population should not exceed $50 \%$ of the potential maximum productivity rate of the population $\left(R_{\max }\right)$, adjusted by a recovery factor $(F)$ which can vary from 0.1 to 1 according to the conservation status of the population ( 0.1 for endangered, 0.5 for threatened, and 1 for other populations; Barlow et al. 1995). PBR is calculated through a simple equation requiring 3 factors: minimum population size $\left(N_{\min }\right), R_{\max }$ and $F$, as follows:

$$
\mathrm{PBR}=0.5 R_{\max } F N_{\min }
$$

For $R_{\max }$, we used maximum population growth rates observed at nesting sites: $0.064 \mathrm{yr}^{-1}$ for loggerheads (Brazil; Marcovaldi \& Chaloupka 2007) and $0.139 \mathrm{yr}^{-1}$ for green turtles (Florida, USA; Chaloupka et al. 2008). These maximum population growth rates were chosen because the observed populations were at low density and are thought to have similar life history traits to the Mediterranean populations of each species. PBR was calculated for each of 3 values of $F(0.1,0.5$, and 1 ; Wade 1998). Although minimum population abundance should be used, we calculated PBR for all mean and 95\% CI abundance estimates of the Mediterranean populations, thereby providing both a range and maximum PBRs in a context with high uncertainty.

\section{Estimated bycatch removal}

Available bycatch data (Table S2 in the Supplement) aggregate Mediterranean green turtles and Mediterranean and Atlantic loggerheads together; as such, they are difficult to compare with PBRs estimated by this study. Data regarding the eastern Mediterranean (29500 deaths $\mathrm{yr}^{-1}$ ) are here considered to be an approximation of the removal level of Mediterranean loggerheads, considering that this subpopulation mostly frequents the eastern basin, while in the western basin, Mediterranean loggerheads mix with Atlantic loggerheads. Data regarding the Levantine basin (8450 deaths $\mathrm{yr}^{-1}$ ) are considered as an approximation of removal levels of Mediterran- 
ean green turtles considering that they mostly frequent the Levantine basin and to a lesser extent other areas of the eastern basin, and that they share the Levantine basin with loggerhead turtles.

\section{RESULTS}

\section{Population demographic structure and abundance}

\section{Loggerhead turtles}

The estimated mean number of adults was 15843 (95\% CI: 6915-31958). The maximum number of
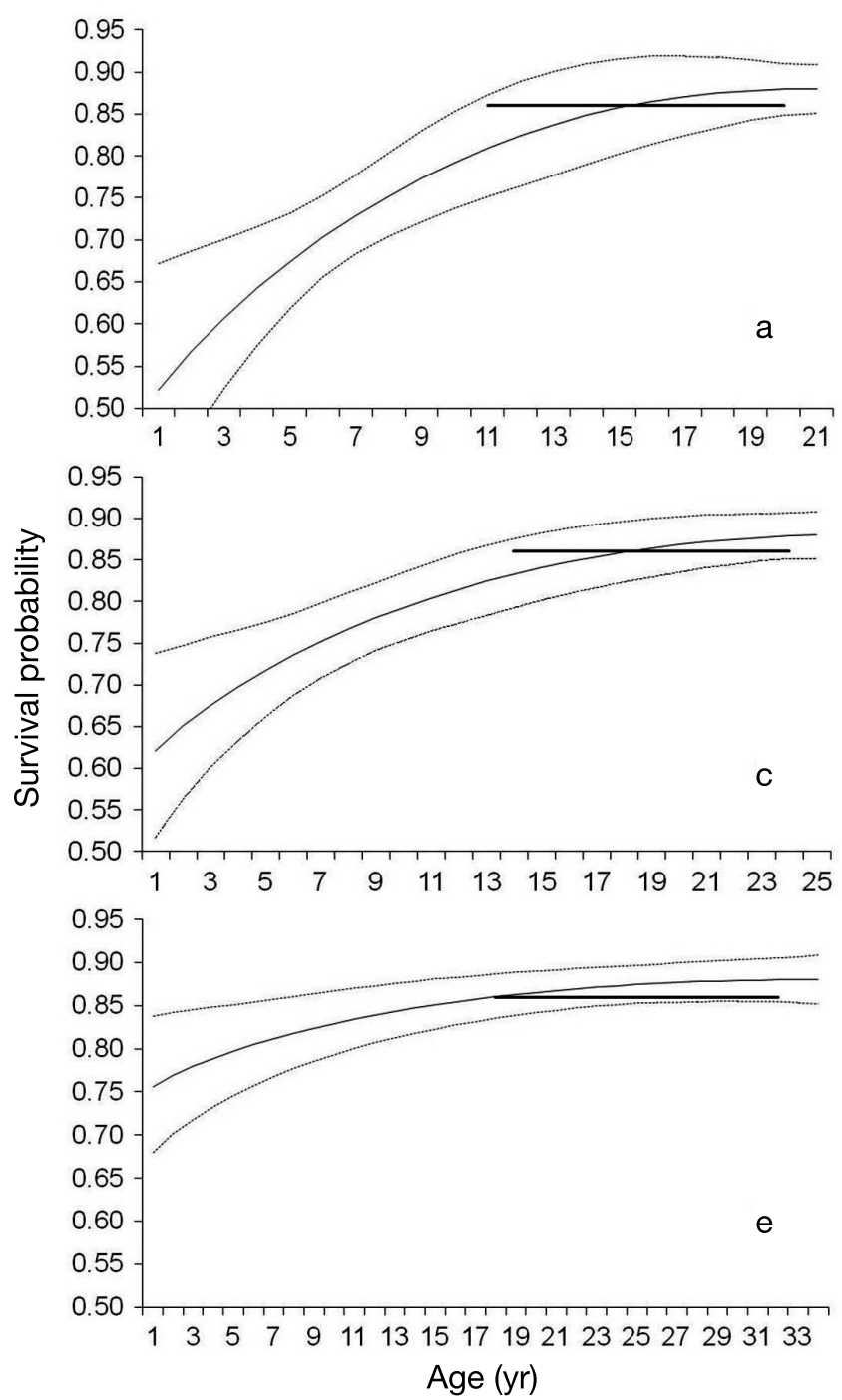

adult age classes, exceeded by only $0.1 \%$ of adults (e.g. Frazer 1983), was 38 (95\% CI: 31-47), which can be considered as the maximum reproductive life span. However, $95 \%$ of adults were included in only 23 age classes (95\% CI: 18-29), and ARL was $8.2 \mathrm{yr}$ (95\% CI: 6.5-10.4; Table S3 in the Supplement). Because the adult model assumed a constant adult survival probability for all age classes, the above estimations should be regarded as maximum values, and somewhat shorter reproductive life spans are expected if the adult survival probability decreases with age.

The effect of a (ASM) on age-specific $S$ is shown in Fig. 2. The resulting ranges of $S$ fit the empirical
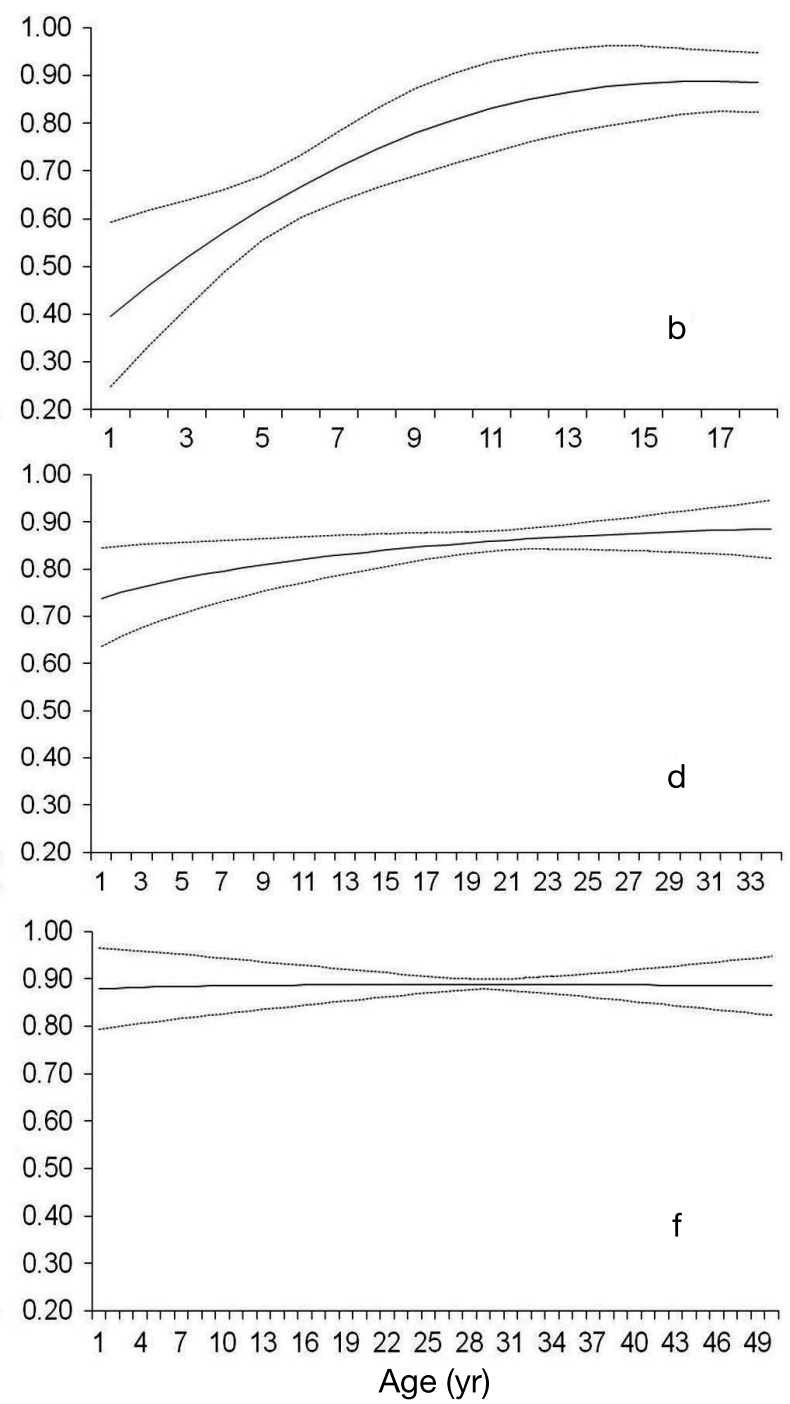

Fig. 2. Mean and $95 \%$ CI of survival probability of $(\mathrm{a}, \mathrm{c}, \mathrm{e})$ loggerhead Caretta caretta and (b,d,f) green turtles Chelonia mydas in each age class from year 1 (hatchlings) to age at sexual maturity (ASM) from the 3 ASM values (loggerheads: 21, 25, and 34 yr; green turtles: 18, 34, and $50 \mathrm{yr}$ ). The solid horizontal bars represent the highest annual survival probability of loggerheads estimated in Mediterranean foraging grounds to date (0.86; Tunisian Shelf; Casale et al. 2015). The bars span the age range to which this probability applies 
estimation of juvenile survival probability (Fig. 2). Combining the results for adults and juveniles, total population abundance estimates for different a values are shown in Fig. 3, and detailed results of 3 specific scenarios with the minimum, mean, and maximum ASM values $(21,25$, and $34 \mathrm{yr})$ are presented in Table 2 and in Fig. S1 in the Supplement. Population abundance was higher with higher $a$, ranging from an average of 1197087 turtles (95\% CI: $805658-$ $1732675)$ with $a=21$, to 2364843 turtles (95\% CI: $1611085-3376104)$ with $a=34$ (Table 2).

\section{Green turtles}

The estimated mean number of adults was 3390 (95\% CI: 1894-6552). The maximum number of adult age classes, exceeded by only $0.1 \%$ of adults (e.g. Frazer 1983), was 42 (95\% CI: 27-73), which can be considered as the maximum reproductive life span. However, $95 \%$ of adults were included in only 26 age classes (95\% CI: 15-50), and ARL was $9.4 \mathrm{yr}$ (95\% CI: 5.5-17.4; Table S3). Because the adult model assumed a constant adult survival probability for all age classes, the above estimations should be regarded as maximum values, and somewhat shorter reproductive life spans are expected if the adult survival probability decreases with age.

The effect of a (ASM) on age-specific $S$ is shown in Fig. 2. Combining the results

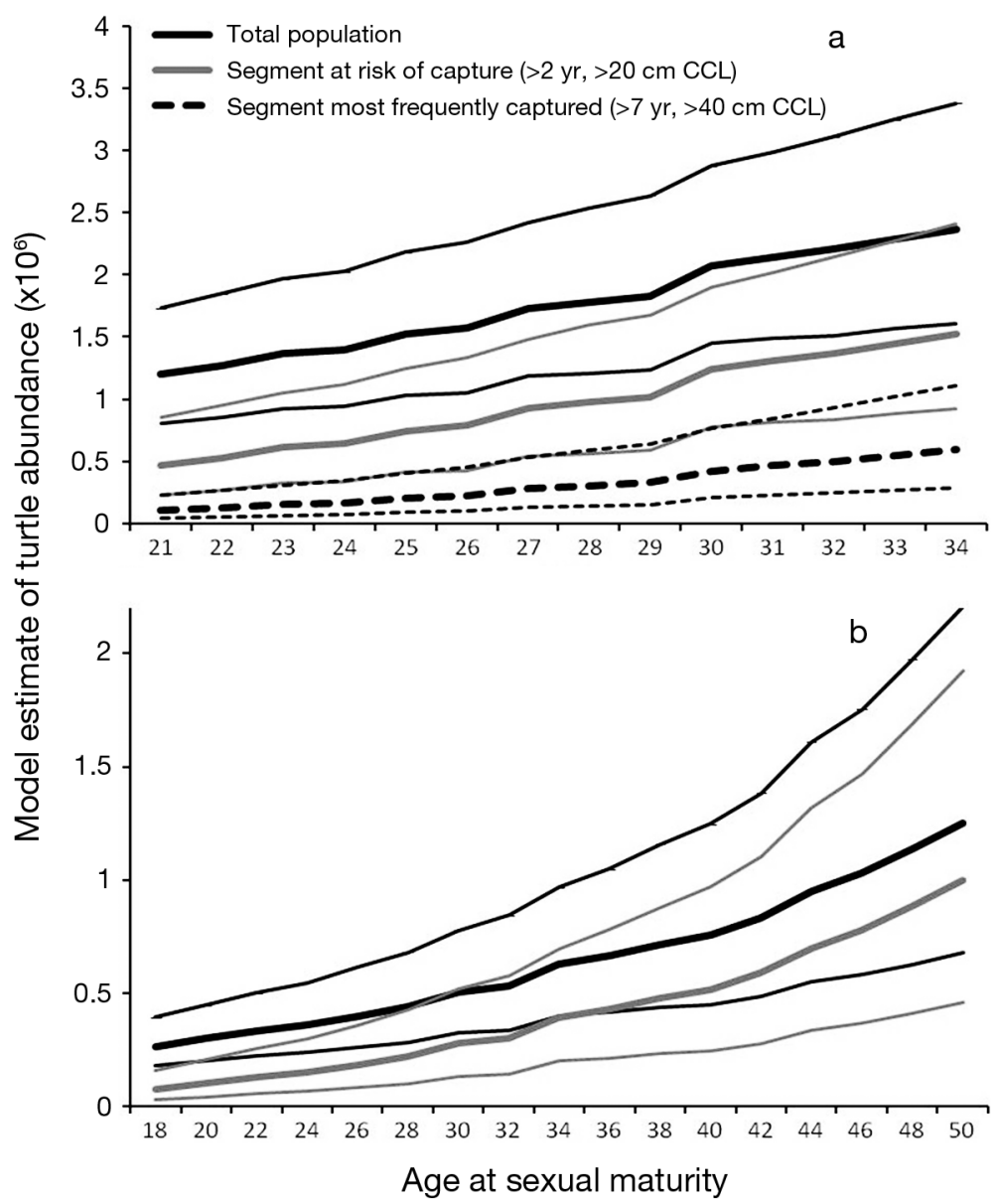

Fig. 3. (a) Estimated loggerhead turtle Caretta caretta population abundance from 14 models with age at sexual maturity (ASM) from 21 to $34 \mathrm{yr}$, and (b) green turtle Chelonia mydas population abundance from 17 models with ASM from 18 to 50 yr (every 2 yr). Mean (thick lines) and $95 \%$ CI (thin lines) are shown for each of the 3 segments of the population: the total population, the fraction of the population that is at risk of capture by fisheries ( $>20 \mathrm{~cm}$ curved carapace length, CCL), and the fraction of the population that is most represented in fisheries bycatch $(>40 \mathrm{~cm}$ CCL). See 'Materials and methods' for further details about these 2 components of the population

Table 2. Abundance (mean and $95 \%$ CI) for the Mediterranean loggerhead Caretta caretta and green turtle Chelonia mydas populations estimated through a stationary age distribution model, for 3 age at sexual maturity (ASM) values. The estimates for the category 'most at risk' of being captured by fisheries are given for loggerheads only, for which growth curves are available in the Mediterranean (see 'Materials and methods')

\begin{tabular}{|lccc|}
\hline ASM $(\mathrm{yr})$ & Total population & Population at risk of capture $(>2$ yr $)$ & Most at risk $(>7 \mathrm{yr})$ \\
\hline Loggerhead turtles & & & \\
21 & $1197087(805658-1732675)$ & $469059(229658-853532)$ & $110550(45276-227072)$ \\
25 & $1521107(1034839-2178790)$ & $744754(414729-1245429)$ & $205913(90533-403324)$ \\
34 & $2364843(1611085-3376104)$ & $1522577(922981-2407930)$ & $597394(290519-1106122)$ \\
Green turtles & & & \\
18 & $261727(176284-391386)$ & $71329(25993-158849)$ & \\
34 & $626196(397537-967649)$ & $388782(198002-692427)$ & \\
50 & $1252283(679433-2209833)$ & $995678(459714-1926281)$ & \\
\hline
\end{tabular}


Table 3. Effect of model parameters on the population abundance estimate (simulated for loggerhead turtles Caretta caretta only). (a) Ratios (corrected:original) of abundance values obtained applying a $20 \%$ correction factor to each parameter (1.2 or 0.8 for parameters with a positive or negative relation to the population abundance, respectively). The effect of age at sexual maturity (ASM) was assessed by comparing ASM = 30 against 25 (mean ASM). (b) Ratios of abundance values obtained fixing each parameter at the minimum and maximum values considered for the model (see Table 1). In both cases, for parameters other than ASM, the model was run by changing 1 parameter at a time with ASM $=25$. Values: the 2 values from which results of the simulation are obtained

\begin{tabular}{|c|c|c|c|c|c|}
\hline (a) & $\begin{array}{l}\text { Correction } \\
\text { factor }\end{array}$ & $\mathrm{N}$ adults & $\begin{array}{c}\text { Total } \\
\text { population }\end{array}$ & $\begin{array}{c}\text { Population } \\
\text { at risk of } \\
\text { capture }(>2 \mathrm{yr})\end{array}$ & $\begin{array}{c}\text { Most at risk } \\
\text { of being } \\
\text { captured }(>7 \mathrm{yr})\end{array}$ \\
\hline $\operatorname{ASM}(a)$ & 1.2 & 1.0 & 1.3 & 1.4 & 1.8 \\
\hline Nests per year $(n)$ & 1.2 & 1.2 & 1.2 & 1.2 & 1.2 \\
\hline Female remigration interval (years/breeding) $(r)$ & 1.2 & 1.2 & 1.0 & 1.1 & 1.1 \\
\hline Nests per female per breeding season $(d)$ & 1.2 & 1.3 & 1.1 & 1.1 & 1.2 \\
\hline Sex ratio (proportion female) $(p)$ & 0.8 & 1.3 & 1.1 & 1.1 & 1.2 \\
\hline Eggs per nest $(f)$ & 0.8 & 1.0 & 1.2 & 1.1 & 1.1 \\
\hline Hatchlings to sea per egg $(g)$ & 1.2 & 1.0 & 1.2 & 1.1 & 1.1 \\
\hline Adult survival $\left(S_{1}\right)$ & 0.8 & 1.0 & 2.3 & 3.3 & 5.5 \\
\hline (b) & Values & $\mathrm{N}$ adults & $\begin{array}{c}\text { Total } \\
\text { population }\end{array}$ & $\begin{array}{c}\text { Population } \\
\text { at risk of } \\
\text { capture }(>2 \mathrm{yr})\end{array}$ & $\begin{array}{c}\text { Most at risk } \\
\text { of being } \\
\text { captured }(>7 \mathrm{yr})\end{array}$ \\
\hline $\operatorname{ASM}(a)$ & 21-34 & 1.0 & 2.0 & 3.2 & 5.4 \\
\hline Nests per year $(n)$ & $7250-8800$ & 1.2 & 1.2 & 1.2 & 1.2 \\
\hline Female remigration interval (years/breeding) $(r)$ & $2.00-3.35$ & 1.6 & 1.1 & 1.2 & 1.4 \\
\hline Nests per female per breeding season $(d)$ & $1-5$ & 5.0 & 1.4 & 1.8 & 3.1 \\
\hline Sex ratio (proportion female) $(p)$ & $0.40-0.75$ & 1.9 & 1.1 & 1.3 & 1.5 \\
\hline Eggs per nest $(f)$ & 73-116 & 1.0 & 1.5 & 1.4 & 1.2 \\
\hline Hatchlings to sea per egg $(g)$ & $0.583-0.666$ & 1.0 & 1.1 & 1.1 & 1.0 \\
\hline Adult survival $\left(S_{1}\right)$ & $0.85-0.91$ & 1.0 & 1.3 & 1.5 & 1.9 \\
\hline Parameter for non-linearity of $S(b)$ & $0.00-0.03$ & 1.0 & 1.4 & 1.9 & 1.9 \\
\hline
\end{tabular}

Table 4. Potential biological removal (PBR) values (number of turtles) calculated from abundance estimations of the Mediterranean loggerhead Caretta caretta and green turtle Chelonia mydas populations at risk of capture (Table 2). Although minimum population abundance should be used, PBRs are provided for the entire range (mean and $95 \% \mathrm{CI}$ ) of abundance estimates, in order to also include maximum PBRs in a context with high uncertainty. PBR was calculated for each of 3 values of the recovery factor $F$ : 0.1 for endangered, 0.5 for threatened, and 1 for other populations (sensu Wade 1998). ASM: age at sexual maturity

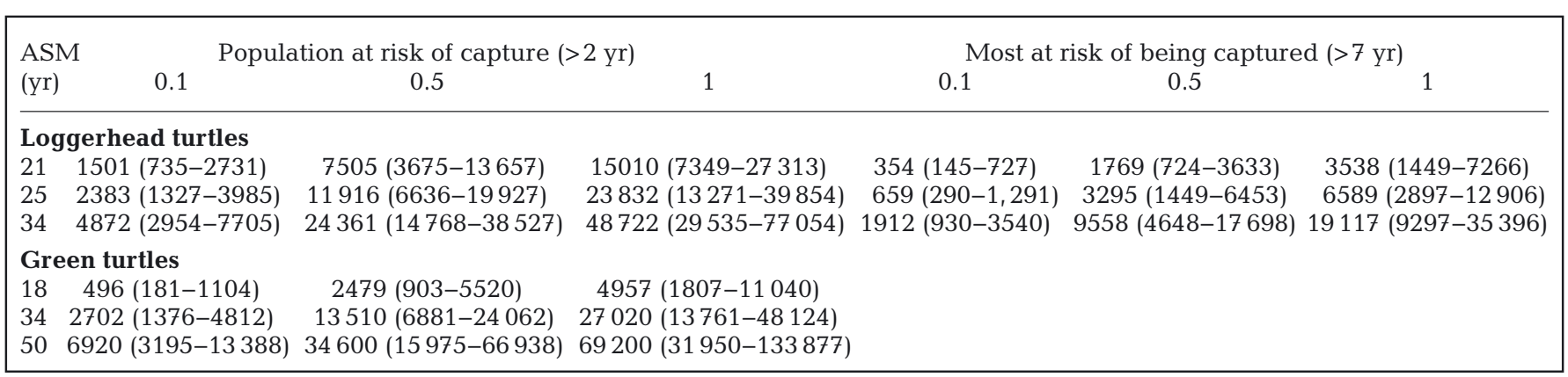

for adults and juveniles, total population abundance estimates for different a values are shown in Fig. 3, and detailed results of 3 specific scenarios with the minimum, mean, and maximum ASM values (18, 34, and 50 yr) are presented in Table 2 and Fig. S2. Population abundance increased with higher $a$, ranging from an average of 261727 turtles (95\% CI: $176284-$ 391386 ) with $a=18$, to 1252283 turtles (95\% CI: 679 433-2 209 833) with $a=50$ (Table 2).
General sensitivity analysis

The biological parameters with the largest effect on population abundance estimates were ASM (a), nests female ${ }^{-1}$ season $^{-1}(d)$, and adult survival probability $\left(S_{1}\right)$ (Table 3$)$. Also, the parameter for non-linearity of $\mathrm{S}(b)$ showed a relatively large effect, indicating that population abundance is strongly affected by how juvenile $S$ changes across age classes. 


\section{Bycatch and PBR}

Loggerhead turtles

Mean PBR estimates varied from 1501 to 48722 loggerhead turtles for the fraction of the population at risk of capture and from 354 to 19117 turtles for the fraction of the population at highest risk of capture (Table 4). PBR sensu stricto (calculated on the minimum population abundance) was lower than the estimated bycatch removal, as were PBRs in most scenarios (Fig. 4). A frequency distribution of PBR results for an example case is shown in Fig. S3.

\section{Green turtles}

Mean PBR estimates varied from 496 to 69200 green turtles for the segment of the population at risk of capture (Table 4). PBR sensu stricto (calculated on the minimum population abundance) was lower than the estimated bycatch removal, as were PBRs in many other scenarios (Fig. 4).

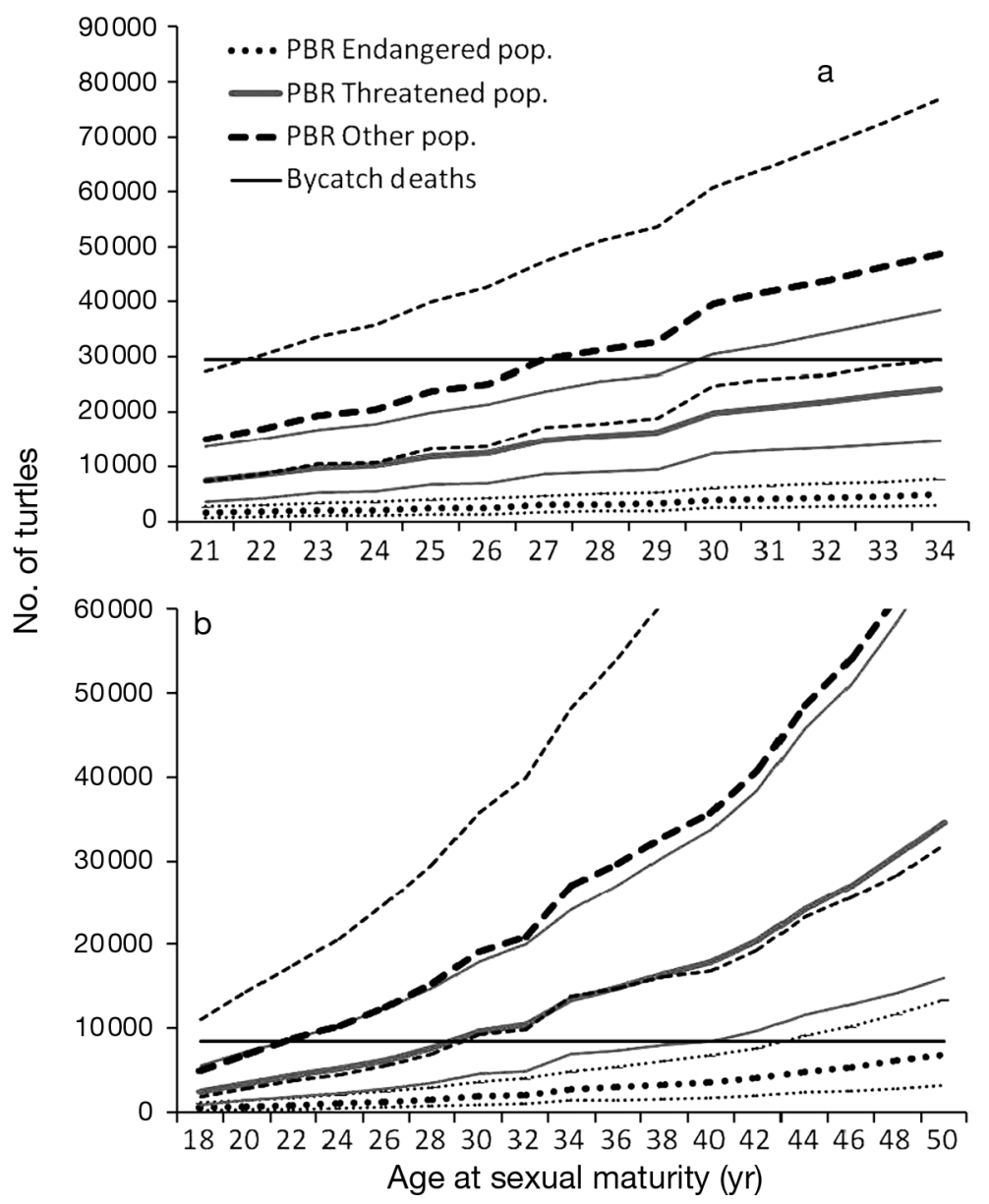

\section{DISCUSSION}

\section{Population demographic structure and abundance}

We simulated the demographic structure of theoretical sea turtle populations with stationary age distributions using independent biological parameters available for the Mediterranean populations of loggerhead and green turtles. This represents the first attempt to estimate population sizes for these populations using a simulated demographic structure. We used wide ranges of values for all parameters, and likely captured the true abundances in our $95 \%$ CI ranges. The most problematic assumption of the model is the stationary age distribution, which is a function of time-constant survival rates and age at maturity. It is improbable that a sea turtle population is perfectly stable and in a stationary condition. In the case of a decreasing or increasing population, the abundance obtained by our stationary age distribution model would be over- and underestimated, respectively. However, the available long-term data sets of nest counts do not show a clear overall trend in the Mediterranean populations (Ilgaz et al. 2007, Türkozan \& Yilmaz 2008, Casale \& Margaritoulis 2010, Margaritoulis et al. 2011); this is even more uncertain for green turtles. Our model also has other simplifications. For instance, all turtles are assumed to enter the adult stage at the same age, and this stage is assumed to have a constant annual survival probability. The theoretical populations are also assumed to be living under natural conditions (although it cannot be excluded that the given values of some independent variables incorporate current anthropogenic effects), while anthropogenic mortality is considered at a second step, by comparing known levels

Fig. 4. Potential biological removal (PBR) levels calculated from abundance levels for the fraction of the population at risk of capture by fisheries $(>20 \mathrm{~cm}$ curved carapace length, CCL or $>2$ yr) of Mediterranean (a) loggerhead Caretta caretta and (b) green turtle Chelonia mydas populations estimated through a stationary age distribution model for a range of age at sexual maturity (ASM) values. Mean (thick lines) and $95 \% \mathrm{CI}$ (thin lines) are shown for each of 3 PBRs calculated for endangered, threatened, and other populations (recovery factor $F=0.1,0.5$, and 1 respectively; see 'Materials and methods' for details). The horizontal solid bar shows the level of removal estimated from bycatch data; therefore, scenarios below the bar should be considered unsustainable 
of anthropogenic mortality with PBR obtained from the simulations. Therefore, the present estimates can be regarded as an attempt to provide an order of magnitude for the abundance of Mediterranean turtle populations, although the exact figures should be considered preliminary.

The adult fraction of the population is the easiest to simulate because it is not subject to highly uncertain parameters such as ASM (or a) and $S$-age relationships in juveniles. The present estimate of annual nesting females is higher than the previous estimate (2280-2787 loggerheads and 339-360 green turtles; Broderick et al. 2002), mainly due to a higher overall nest count resulting from increased beach monitoring efforts. The estimated average ARL of loggerheads was $8.2 \mathrm{yr}$; with the average ASM (25 yr), this suggests an average adult age of $33 \mathrm{yr}$. Considering the ARL and ASM ranges, the average adult age would range from 28 to $44 \mathrm{yr}$. For green turtles, ARL was $9.4 \mathrm{yr}$, but ASM for the Mediterranean population is too uncertain to suggest adult age. An ARL of a few years may appear short for sea turtles, which are considered long-lived animals. However, such a consideration confounds 2 very different concepts, the potential life span (that can be long but is reached by only a small percentage of a population) and the average life span. In sea turtles, the average life span is predicted to be just a few years, i.e. most turtles never reach maturity nor even a large size. For instance, in our model, adults represent only about $1 \%$ of the total population (see also Heppell et al. 1996). In the same way, only a few adults are expected to live for decades. For example, with the adult $S$ considered here, only about $5 \%$ of adults would live longer than $23 \mathrm{yr}$ after ASM, which means longer than $48 \mathrm{yr}$ in total lifespan if ASM is $25 \mathrm{yr}$. As a different perspective to think about ARL, consider that an adult female should lay an average of 10 (loggerheads) or 11 clutches (green turtles) to produce enough eggs to allow 2 of her offspring to reach ASM in order to replace herself and her mate. Any additional clutches would lead to population increase. With the average values for remigration interval and clutches female ${ }^{-1}$ season $^{-1}$ (Table 1 ), the above number of clutches can be translated to 12.1 and $11 \mathrm{yr}$ ARL, respectively. However, these values are probably overestimates, because current estimation of remigration intervals and clutches female ${ }^{-1}$ are probably over- and underestimated, respectively, due to methodological biases. Adult life spans depend on survival probabilities that might be underestimated because of methodological limits, as suggested by Chaloupka \& Limpus (2002). However, if current methods underestimate survival probabilities in adults and juveniles, and the actual values are higher than the available estimates, then even fewer nests would be needed to replace an adult couple, and adults would breed for much longer than 'required.'

Our model considered juvenile $S$ to be a variable dependent on age (size) and derived from other independent variables. For loggerheads, the estimated values of $S$ (Fig. 2) can be compared to values estimated through empirical means from Mediterranean foraging grounds (Casale et al. 2015). The highest of these values can be assumed to be less affected by anthropogenic mortality and closer to the natural values, and this value is similar to the survival probabilities estimated by our model. For comparison, the highest $S$ values for juveniles of other loggerhead populations are around 0.91 (Casale et al. 2015).

Population abundance estimates span a wide range of values, due to the uncertainty in several parameters. Empirical estimates are intrinsically difficult to provide for a marine animal spending most of the time underwater. The best method may be represented by aerial surveys that can estimate the surface abundance of turtles, followed by an estimate of the total abundance in the surveyed area through a correction factor for the time spent underwater. However, aerial surveys have been conducted in only 2 areas, representing just a small part of the Mediterranean: in Spanish waters (Gómez de Segura et al. 2006) and in the Pelagos Sanctuary (Lauriano et al. 2011), both in the western Mediterranean. In these 2 areas, 19000 and 10000 loggerhead turtles were estimated to occur, respectively, but these areas are frequented by loggerheads of both Mediterranean and Atlantic origin (Clusa et al. 2014). For all of the above limitations, a comparison between simulated and empirical estimates is not very informative at present.

\section{Bycatch and PBR}

Population abundance estimates from our model can be compared to estimated bycatch levels and associated mortality in the Mediterranean. Available bycatch estimates (Casale 2011) are based on data collected in different Mediterranean areas in the 1990 s and 2000s; therefore, current bycatch levels might be different. However, the population abundance estimates here were derived from average nest counts and other data collected during the same period as the bycatch estimates. Bycatch levels are probably underestimated, and mortality rates have a 
degree of uncertainty (Casale 2011). The empirical estimates are aggregates of Mediterranean loggerheads, Atlantic loggerheads (mainly in the western basin; Clusa et al. 2014), and Mediterranean green turtles, the latter occurring mainly in the Levantine Basin (Casale \& Margaritoulis 2010). Thus, it is likely that a few tens of thousands of Mediterranean loggerheads and several thousands of green turtles are removed annually by fisheries. This amount is higher than the PBR values (sensu stricto, i.e. calculated on the minimum population abundance) for the segment of the population at risk of capture and even higher than most PBRs calculated on the highest population abundance estimates. Therefore, our results indicate that the available bycatch level should be regarded as unsustainable for the Mediterranean turtle populations, as previously suspected (Casale 2011). Under this scenario, the lack of evidence (from the primary nesting beaches) of a decreasing population is intriguing. We propose 3 hypotheses for further study: (1) the real abundance, and hence PBR, is higher than we thought because of major rookeries that have not yet been discovered (Libya is the best candidate for unknown rookeries; Hamza 2010); (2) the real abundance of juveniles (the bulk of the population), and hence PBR, is higher than we thought because the population is increasing (while our model considers a stable population with constant recruitment), but these abundant juvenile age classes have not yet recruited to the adult stage (the only current index of the population through nest counts); this would imply a reduction of anthropogenic impact in a recent period $(<\mathrm{ASM})$, and the best candidate for this is protection of nesting beaches with increased natality (Casale \& Margaritoulis 2010); (3) the juvenile population is actually decreasing due to an increase in bycatch mortality in a recent period $(<\mathrm{ASM})$, but this has not yet been observed in the adult stage because of the long maturation of these animals. Although most bycatch studies have been conducted within this period (Casale 2011), it is likely that high bycatch levels also occurred before; however, a recent increase cannot be excluded, especially if this is due to cryptic fisheries bycatch in small-scale fisheries in developing countries.

\section{Concluding remarks}

By forcing the population to be stable in structure and abundance, a stationary age distribution model highlights the interdependency among several demographic parameters of a population and helps iden- tify the minimum set of fundamental parameters (or field data) which are required to describe the population. Our model considered juvenile annual survival probability as a dependent variable (1 for each age class) obtained from 8 independent variables, of which 7 can be obtained at nesting beaches and 1 (ASM) from studies on juveniles. In our model, ASM, annual survival probability of adults, and nests female $^{-1}$ season $^{-1}$ are the most influential parameters for the abundance results, either in terms of the current range of uncertainty or in terms of a constant percentage change, or both. Therefore, these parameters should be considered as a research priority to better define the most common range of their values. A better assessment of the other parameters could also greatly reduce the overall uncertainty, as would other information to make the models more realistic. For instance, the proportion of female neophytes (first-time breeders) observed at nesting grounds can provide a direct estimate of $A_{V}$ and provide useful indications about population trends (e.g. Stokes et al. 2014) that can be used or compared in population models. Abundance estimates at sea by aerial surveys at most of the major foraging grounds will be particularly needed in the future to compare with simulations and to provide trends of the juvenile age classes, which may represent a better abundance index than nest counts. Sea turtle populations consist almost entirely of juveniles which, with some exceptions, cannot be accessed by land. Monitoring, defining conservation strategies, and managing sea turtle populations on the basis of the adult fraction of the populations or its indices (nests) is not realistic, and more effort should be applied to the investigation of demography and abundance (National Research Council 2010).

Acknowledgements. We thank 5 anonymous reviewers for their valuable comments on the first submitted version of the manuscript, and M. Ramirez and B. Chasco for comments on an early draft.

\section{LITERATURE CITED}

Avens L, Snover ML (2013) Age and age estimation in sea turtles. In: Wyneken J, Lohmann KJ, Musick JA (eds) The biology of sea turtles, Vol III. CRC Press, Boca Raton, FL, p 97-133

Barlow J, Swartz SL, Eagle TC, Wade PR (1995) US marine mammals stock assessments: guidelines for preparation, background, and a summary of the 1995 assessments. US Dep Comm, NOAA Tech Memo, National Marine Fisheries Service, Office of Protected Resources 6:1-73

Broderick AC, Glen F, Godley BJ, Hays GC (2002) Estimating the number of green and loggerhead turtles nesting 
annually in the Mediterranean. Oryx 36:227-235

Broderick AC, Glen F, Godley BJ, Hays GC (2003) Variation in reproductive output of marine turtles. J Exp Mar Biol Ecol 288:95-109

> Campbell CL, Lagueux CJ (2005) Survival probability estimates for large juvenile and adult green turtles (Chelonia mydas) exposed to an artisanal marine turtle fishery in the western Caribbean. Herpetologica 61:91-103

Carr A, Goodman D (1970) Ecologic implications of size and growth in Chelonia. Copeia 1970:783-786

Carreras C, Pascual M, Cardona L, Marco A and others (2011) Living together but remaining apart: Atlantic and Mediterranean loggerhead sea turtles (Caretta caretta) in shared feeding grounds. J Hered 102:666-677

> Casale P (2011) Sea turtle by-catch in the Mediterranean. Fish Fish 12:299-316

Casale P, Margaritoulis D (eds) (2010) Sea turtles in the Mediterranean: distribution, threats and conservation priorities. IUCN, Gland

> Casale P, Gerosa G, Yerli SV (2000) Female-biased primary sex ratio of the green turtle, Chelonia mydas, estimated through sand temperatures at Akyatan, Turkey. Zool Middle East 20:37-46

Casale P, Nicolosi P, Freggi D, Turchetto M, Argano R (2003) Leatherback turtles (Dermochelys coriacea) in Italy and in the Mediterranean basin. Herpetol J 13:135-139

Casale P, Freggi D, Basso R, Argano R (2005) Size at male maturity, sexing methods and adult sex ratio in loggerhead turtles (Caretta caretta) from Italian waters investigated through tail measurements. Herpetol J 15:145-148

Casale P, Lazar B, Pont S, Tomás J and others (2006) Sex ratios of juvenile loggerhead sea turtles Caretta caretta in the Mediterranean Sea. Mar Ecol Prog Ser 324: 281-285

Casale P, Mazaris AD, Freggi D, Basso R, Argano R (2007) Survival probabilities of loggerhead sea turtles (Caretta caretta) estimated from capture-mark-recapture data in the Mediterranean Sea. Sci Mar 71:365-372

Casale P, Abbate G, Freggi D, Conte N, Oliverio M, Argano $\mathrm{R}$ (2008) Foraging ecology of loggerhead sea turtles Caretta caretta in the central Mediterranean Sea: evidence for a relaxed life history model. Mar Ecol Prog Ser 372:265-276

Casale P, d'Astore PP, Argano R (2009a) Age at size and growth rates of early juvenile loggerhead sea turtles (Caretta caretta) in the Mediterranean based on length frequency analysis. Herpetol J 19:29-33

> Casale P, Mazaris AD, Freggi D, Vallini C, Argano R (2009b) Growth rates and age at adult size of loggerhead sea turtles (Caretta caretta) in the Mediterranean Sea, estimated through capture-mark-recapture records. Sci Mar 73:589-595

> Casale P, Affronte M, Insacco G, Freggi D and others (2010) Sea turtle strandings reveal high anthropogenic mortality in Italian waters. Aquat Conserv 20:611-620

> Casale P, Conte N, Freggi D, Cioni C, Argano R (2011a) Age and growth determination by skeletochronology in loggerhead sea turtles (Caretta caretta) from the Mediterranean Sea. Sci Mar 75:197-203

> Casale P, Mazaris AD, Freggi D (2011b) Estimation of age at maturity of loggerhead sea turtles Caretta caretta in the Mediterranean using length-frequency data. Endang Species Res 13:123-129

Casale P, Freggi D, Maffucci F, Hochscheid S (2014) Adult sex ratios of loggerhead sea turtles (Caretta caretta) in two Mediterranean foraging grounds. Sci Mar 78: 303-309

Casale P, Freggi D, Furii G, Vallini C and others (2015) Annual survival probabilities of juvenile loggerhead sea turtles indicate high anthropogenic impact on Mediterranean populations. Aquat Conserv 25:551-561

Caswell H, Brault S, Read AJ, Smith TD (1998) Harbor porpoise and fisheries: an uncertainty analysis of incidental mortality. Ecol Appl 8:1226-1238

> Chaloupka MY, Limpus CJ (2002) Survival probability estimates for the endangered loggerhead sea turtle resident in southern Great Barrier Reef waters. Mar Biol 140: 267-277

> Chaloupka M, Limpus C (2005) Estimates of sex- and ageclass-specific survival probabilities for a southern Great Barrier Reef green sea turtle population. Mar Biol 146: 1251-1261

Chaloupka M, Bjorndal KA, Balazs GH, Bolten AB and others (2008) Encouraging outlook for recovery of a once severely exploited marine megaherbivore. Glob Ecol Biogeogr 17:297-304

> Clusa M, Carreras C, Pascual M, Gaughran SJ and others (2014) Fine-scale distribution of juvenile Atlantic and Mediterranean loggerhead turtles (Caretta caretta) in the Mediterranean Sea. Mar Biol 161:509-519

Crouse DT, Crowder LB, Caswell H (1987) A stage-based population model for loggerhead sea turtles and implications for conservation. Ecology 68:1412-1423

Crowder LB, Crouse DT, Heppell SS, Martin TH (1994) Predicting the impact of turtle excluder devices on loggerhead sea-turtle populations. Ecol Appl 4:437-445

> Curtis KA, Moore JE (2013) Calculating reference points for anthropogenic mortality of marine turtles. Aquat Conserv 23:441-459

Dethmers KEM, Baxter PWJ (2011) Extinction risk analysis of exploited green turtle stocks in the Indo-Pacific. Anim Conserv 14:140-150

Frazer NB (1983) Survivorship of adult female loggerhead sea turtles, Caretta caretta, nesting on Little Cumberland Island, Georgia, USA. Herpetologica 39:436-447

Frazer NB (1986) Survival from egg to adulthood in a declining population of loggerhead turtles, Caretta caretta. Herpetologica 42:47-55

Godley BJ, Broderick AC, Downie JR, Glen F and others (2001) Thermal conditions in nests of loggerhead turtles: further evidence suggesting female skewed sex ratios of hatchling production in the Mediterranean. J Exp Mar Biol Ecol 263:45-63

Gómez de Segura A, Tomás J, Pedraza SN, Crespo EA, Raga JA (2006) Abundance and distribution of the endangered loggerhead turtle in Spanish Mediterranean waters and the conservation implications. Anim Conserv 9:199-206

Goshe LR, Avens L, Scharf FS, Southwood AL (2010) Estimation of age at maturation and growth of Atlantic green turtles (Chelonia mydas) using skeletochronology. Mar Biol 157:1725-1740

Hamza A (2010) Libya. In: Casale P, Margaritoulis D (eds) Sea turtles in the Mediterranean: distribution, threats and conservation priorities. IUCN, Gland, p 157-170

> Hays GC (2000) The implications of variable remigration intervals for the assessment of population size in marine turtles. J Theor Biol 206:221-227

Hays GC, Fossette S, Katselidis KA, Schofield G, Gravenor MB (2010) Breeding periodicity for male sea turtles, 
operational sex ratios, and implications in the face of climate change. Conserv Biol 24:1636-1643

Heppell SS, Limpus CJ, Crouse DT, Frazer NB, Crowder LB (1996) Population model analysis for the loggerhead sea turtle, Caretta caretta, in Queensland. Wildl Res 23: 143-159

Heppell SS, Snover ML, Crowder LB (2002) Sea turtle population ecology. In: Lutz PL, Musick JA, Wyneken J (eds) The biology of sea turtles, Vol II. CRC Marine Biology Series. CRC Press, Boca Raton, FL, p 275-306

Heppell SS, Crouse DT, Crowder LB, Epperly SP and others (2005) A population model to estimate recovery time, population size, and management impacts on Kemp's ridley sea turtles. Chelonian Conserv Biol 4:767-773

Ilgaz Ç, Türkozan O, Özdemir A, Kaska Y, Stachowitsch M (2007) Population decline of loggerhead turtles: two potential scenarios for Fethiye beach, Turkey. Biodivers Conserv 16:1027-1037

Kaska Y, Downie R, Tippett R, Furness RW (1998) Natural temperature regimes for loggerhead and green turtle nests in the eastern Mediterranean. Can J Zool 76: 723-729

Lamont MM, Fujisaki I, Carthy RR (2014) Estimates of vital rates for a declining loggerhead turtle (Caretta caretta) subpopulation: implications for management. Mar Biol 161:2659-2668

Lauriano G, Panigada S, Casale P, Pierantonio N, Donovan GP (2011) Aerial survey abundance estimates of the loggerhead sea turtle Caretta caretta in the Pelagos Sanctuary, northwestern Mediterranean Sea. Mar Ecol Prog Ser 437:291-302

Limpus CJ (1990) Puberty and first breeding in Caretta caretta. In: Richardson TH, Richardson JI, Donnelly M (eds) Proc 10th Annu Workshop Sea Turtle Biology and Conservation. Tech Memo NMFS-SEFC-278. NOAA, Miami, FL, p 81-83

Limpus C, Chaloupka M (1997) Nonparametric regression modelling of green sea turtle growth rates (southern Great Barrier Reef). Mar Ecol Prog Ser 149:23-34

Marcovaldi MA, Chaloupka M (2007) Conservation status of the loggerhead sea turtle in Brazil: an encouraging outlook. Endang Species Res 3:133-143

Margaritoulis D (2005) Nesting activity and reproductive output of loggerhead sea turtles, Caretta caretta, over 19 seasons (1984-2002) at Laganas Bay, Zakynthos, Greece: the largest rookery in the Mediterranean. Chelonian Conserv Biol 4:916-929

Margaritoulis D, Argano R, Baran I, Bentivegna F and others (2003) Loggerhead turtles in the Mediterranean Sea: present knowledge and conservation perspectives. In: Bolten AB, Witherington B (eds) Loggerhead sea turtles. Smithsonian Institution Press, Washington, DC, p 175-198

Margaritoulis D, Rees AF, Dean CJ, Riggall T (2011) Reproductive data of loggerhead turtles in Laganas Bay, Zakynthos Island, Greece, 2003-2009. Mar Turtle Newsl 131:2-6

Mazaris AD, Matsinos YG (2006) An individual based model of sea turtles: investigating the effect of temporal variability on population dynamics. Ecol Model 194:114-124

> Mazaris AD, Kornaraki E, Matsinos GY, Margaritoulis D

Editorial responsibility: Jeffrey Seminoff,

La Jolla, California, USA
(2004) Modeling the effect of sea surface temperature on sea turtle nesting activities by investigating seasonal trends. Nat Resour Model 17:445-465

Monk MH, Berkson J, Rivalan P (2011) Estimating demographic parameters for loggerhead sea turtles using mark-recapture data and a multistate model. Popul Ecol 53:165-174

National Research Council (2010) Assessment of sea-turtle status and trends: integrating demography and abundance. The National Academy Press, Washington, DC

Özdemir A, Türkozan O, Güçlü Ö (2008) Embryonic mortality in loggerhead turtle (Caretta caretta) nests: a comparative study on Fethiye and Goksu Delta Beaches. Turk J Zool 32:287-292

> Piovano S, Clusa M, Carreras C, Giacoma C, Pascual M, Cardona L (2011) Different growth rates between loggerhead sea turtles (Caretta caretta) of Mediterranean and Atlantic origin in the Mediterranean Sea. Mar Biol 158: 2577-2587

Rees AF, Margaritoulis D (2004) Beach temperatures, incubation durations and estimated hatchling sex ratio for loggerhead sea turtle nests in southern Kyparissia bay, Greece. Testudo 6:23-36

Rees AF, Margaritoulis D, Newman R, Riggall TE, Tsaros P, Zbinden JA, Godley BJ (2013) Ecology of loggerhead marine turtles Caretta caretta in a neritic foraging habitat: movements, sex ratios and growth rates. Mar Biol 160:519-529

Solow AR, Bjorndal KA, Bolten AB (2002) Annual variation in nesting numbers of marine turtles: the effect of sea surface temperature on re-migration intervals. Ecol Lett 5:742-746

Stokes KL, Fuller WJ, Glen F, Godley BJ and others (2014) Detecting green shoots of recovery: the importance of long-term individual-based monitoring of marine turtles. Anim Conserv 17:593-602

Tomás J, Gozalbes P, Raga JA, Godley BJ (2008) Bycatch of loggerhead sea turtles: insights from 14 years of stranding data. Endang Species Res 5:161-169

Türkozan O, Yilmaz C (2008) Loggerhead turtles, Caretta caretta, at Dalyan Beach, Turkey: nesting activity (20042005) and 19-year abundance trend (1987-2005). Chelonian Conserv Biol 7:178-187

Türkozan O, Taskavak E, Ilgaz C (2003) A review of the biology of the loggerhead turtle, Caretta caretta, at five major nesting beaches on the south-western Mediterranean coast of Turkey. Herpetol J 13:27-33

> Türkozan O, Yamamoto K, Yilmaz C (2011) Nest site preference and hatching success of green (Chelonia mydas) and loggerhead (Caretta caretta) sea turtles at Akyatan Beach, Turkey. Chelonian Conserv Biol 10:270-275

- Wade PR (1998) Calculating limits to the allowable humancaused mortality of cetaceans and pinnipeds. Mar Mamm Sci 14:1-37

- Wallace BP, DiMatteo AD, Bolten AB, Chaloupka MY and others (2011) Global conservation priorities for marine turtles. PLoS ONE 6:e24510

Zbinden JA, Davy C, Margaritoulis D, Arlettaz R (2007) Large spatial variation and female bias in the estimated sex ratio of loggerhead sea turtle hatchlings of a Mediterranean rookery. Endang Species Res 3:305-312

Submitted: July 13, 2015; Accepted: November 25, 2015

Proofs received from author(s): January 16, 2016 